\title{
CONCEPTION AND CONSTRUCTION OF AN IMPACT MACHINE (100KJ) FOR FRONTAL AND SKEW SHOCKS
}

\author{
Etienne Pecquet ${ }^{1}$, Jérôme Tchuindjang ${ }^{2}$ and Serge Cescotto ${ }^{1}$ \\ ${ }^{1}$ Department ArGEnCo - Solids, Structures and Fluids Mechanics - University of Liège \\ ${ }^{2}$ Department A\&M - Metallurgy and Materials Science - University of Liège \\ ${ }^{1 \& 2}$ Bât. B52/3 - 1, Chemin des Chevreuils - B-4000 Liège, Belgium \\ Etienne.Pecquet@ulg.ac.be, J.Tchuindjang@ulg.ac.be, Serge.Cescotto@ulg.ac.be
}

The conception and the construction of an impact machine are financed by the Communaute Française de Belgique. This is performed in a fundamental research that deals on metallic macro foams. These products are obtained assembling together pieces of metal with big voices between pieces. Then, energy dissipation can be obtained by plastic deformations. The products can imply direct re-use of metal like old soft drink cans, wires, ... allowing energy saving in comparison with return to the electric furnace. Low cost products are searched for applications in road safety and in civil engineering.

Often, to characterize products in dynamic or impact loading, especially for road safety products, two opposite tests exist: tests on small specimen and with relatively low energy absorption or complete crash tests that are very expensive. Here, the goal is developing a machine between these two situations. So, this machine will allow to best developments of products and then saving money by reducing missed tests in real scales.

The global concept consists in using the height of the laboratory to create the kinetic energy. So, a big slide (400mm in width maintained by a beam HEB300) is constructed on which the mass moves from the top to the cellar of the laboratory. Figure 1 gives a schematic view of the slide. Geometry is also studied to obtain horizontal shocks like in road crashes.

The maximum impact load of this equipment is about $700 \mathrm{~kg}$. Because of the $15 \mathrm{~m}$ in height of the laboratory, the maximum theoretical speed is given by equation 1 . The maximum energy available is given by equation 2 .

$$
\begin{aligned}
& \mathrm{V}=\sqrt{2 \cdot \mathrm{g} \cdot \mathrm{H}}=17,1 \mathrm{~m} / \mathrm{s} \approx 60 \mathrm{~km} / \mathrm{h} \\
& E=m \cdot g \cdot H=100 \mathrm{~kJ}
\end{aligned}
$$

These performances should be a little bit reduced by frictions. Normally, these ones will be small because of metallic punctual contacts only. Mass and impact speed can be chosen freely because mass can be easily adapted and dropped from each height. 


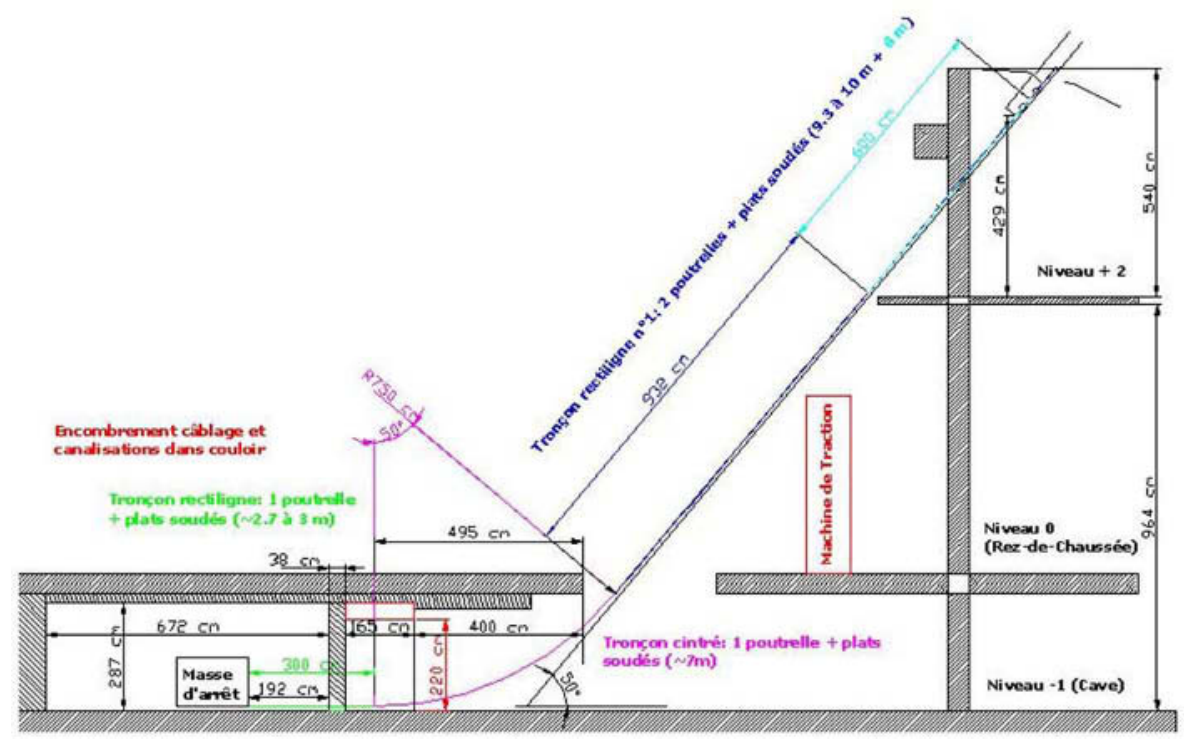

FIGURE 1. Schematic view of the slide.

The impact mass is a wagon only putted on the slide. Many shapes and materials can be mounted on this wagon. The maximum front area of the wagon is $1,60 \mathrm{~m}$ in width and $1 \mathrm{~m}$ in height. A second wagon, fixed behind the first one, allows, by ball bearings all around the slide, to maintain the right trajectory.

When the impact mass comes in the cellar, both wagons are disconnected and the guide wagon is stopped by dampers. Then, the impact mass can crush the specimen choosing freely its trajectory as well during crushing as during the rebound.

In the cellar, the testing zone is a large metallic horizontal floor measuring $6 \times 6,5 \mathrm{~m}$. On it, eight metallic slabs, each one with a mass of three tons, are placed as we want to maintain the specimen to crush. Because of the important modularity of this floor, the great interest of this machine is the availability to do skew shocks.

So, many products for road safety can be tested : bumpers in frontal or skew shocks, safety barriers, ends of these barriers, whole types of shock absorbers, ... Especially concerning safety barriers in metal, as well the cable effect in the barrier as the rebound of the mass after the shock can be examined.

For measurements, the main part will be done with high speed cameras. In addition, force sensors, displacement sensors, accelerometers or other techniques can be added. 